\title{
POVOS INDÍGENAS E O DIREITO À SAÚDE: ACESSO, INSEGURANÇA E CENÁRIO POLÍTICO BRASILEIRO
}

\author{
INDIGENOUS PEOPLES AND THE RIGHT TO HEALTH: \\ ACCESS, INSECURITY AND BRAZILIAN POLITICAL SCENARIO
}

\section{PUEBLOS INDÍGENAS Y DERECHO A LA SALUD: ACCESO, INSEGURIDAD Y ESCENARIO POLÍTICO BRASILEÑO}

\author{
Silvia Angela Gugelmin ${ }^{1}$ \\ Jhéssika Angel Alves e Silva²
}

Como citar este artigo: Gugelmin SA, Silva JAA. Povos indígenas e o direito à saúde: acesso, insegurança e cenário político brasileiro. Rev baiana enferm. 2021;35:e42326.

A construção das trajetórias e vivências dos povos indígenas no Brasil, desde a colonização até os dias atuais, ocorreu por processos de resistência, enfrentamento e confronto para conquista, garantia e consolidação dos direitos sociais, como também do próprio direito à existência. Para melhor compreensão do cenário atual da política de saúde para os povos indígenas brasileiros, cabem alguns apontamentos históricos.

A política indigenista instituída no Brasil como política de Estado foi iniciada com o Serviço de Proteção ao Índio (SPI) em 1910, sendo substituída pela Fundação Nacional do Índio (Funai) em 1967. Esta política partia do pressuposto de que era necessário assegurar mínimas condições de vida a essas populações. No entanto, tinha como base a ideia de que esse era um grupo que estava em processo de desaparecimento e que, com o passar do tempo, iria integrar-se ao restante da sociedade. Neste sentido, essa era uma política emergencial, planejada com um caráter transitório.

Em 1973 foi publicado o Estatuto do Índio ${ }^{(1)}$, que tinha como objetivo regular "[...] a situação jurídica dos índios ou silvícolas e das comunidades indígenas, com o propósito de preservar a sua cultura e integrá-los, progressiva e harmoniosamente, à comunhão nacional". Nesse documento evidenciou-se a atitude tutelar e assimilacionista do Estado no que se referia aos povos indígenas. O estatuto, na prática, colocava nas mãos do órgão indigenista todo o poder de decisão e retirava dos indígenas qualquer possibilidade de autonomia.

Esse cenário foi se modificando com a promulgação da Constituição Federal (CF) em 1988. O cap. VIII Dos Índios, artigo 231, permitiu dar-se um passo importante no reconhecimento dos direitos indígenas no que se refere a "[...] sua organização social, costumes, línguas, crenças, tradições, e os direitos originários sobre as terras que tradicionalmente ocupam $[. . .]^{,(2)}$. Este importante ato não resolveria os problemas, percalços e espólios que os indígenas sofreram historicamente, mas acenava para a possível

\footnotetext{
Nutricionista. Doutora em Ciências. Professor Associado da Universidade Federal do Mato Grosso. Cuiabá, Mato Grosso, Brasil. silviagugelmin@ufmt.br. http://orcid. org/0000-0003-4246-4332.

Antropóloga. Mestre em Antropologia. Universidade Federal de Campina Grande. Campina Grande, Paraíba, Brasil. http://orcid.org/0000-0002-7379-4548.
} 
construção da autonomia indígena, pois abria espaço para o fim da tutela com a autorrepresentação jurídica e política desses grupos.

Todos os governos que sucederam a publicação da CF não obtiveram êxito no processo de consolidação dos direitos constitucionais desses povos. Apesar dos avanços das últimas décadas, os povos indígenas permaneceram em situação de vulnerabilidade social, pois, constantemente, tiveram (e ainda) têm seus direitos questionados e ameaçados.

Um exemplo disso foi a Proposta de Emenda Constitucional (PEC) n. $215^{(3)}$, que circulava no Congresso Nacional desde os anos 2000 e propunha a modificação de dois artigos da CF, os arts. 49 e 231. A proposta tinha a finalidade de atribuir ao Congresso Nacional a competência exclusiva de aprovar as demarcações de terras indígenas, transformando, assim, o ato jurídico da demarcação em um ato político subordinado aos interesses parlamentares. Durante muitos anos, essa proposta circulou no Congresso de forma secundária, porém, com o crescimento da Frente Parlamentar Agropecuária (Bancada Ruralista), foi ganhando força. Até o momento, entretanto, a mobilização social e os povos indígenas têm conseguido frear tais iniciativas.

É importante sinalizar que o direito fundamental dos povos indígenas no Brasil ao seu território é um dos principais alvos nesse processo de desmonte da política indigenista. Visto que a terra indígena não é apenas um lugar de moradia ou de reprodução social, mas também é um espaço cosmológico, que empresta sentido à existência, esse território é um direito inalienável. Como declara Casé Angatu Xukuri Tubinambá, "nós não somos donos da terra, nós somos a terra" ${ }^{(4)}$. Assim, a ideia de viver, ou melhor, de "bem viver", parte desse ocupar e relacionar-se com o território, inclusive no que diz respeito às questões de saúde.

Outro exemplo característico desse cenário foi o Parecer n. 001/2017 $7^{(5)}$, conhecido como Parecer do Genocídio, que propunha o impedimento da redefinição dos limites territoriais e institucionalizava o Marco Territorial. Isto é, só teriam direito às suas terras aqueles povos indígenas que estivessem nesses territórios na data de 5 de outubro de 1988, data da promulgação da CF.

Ambas as iniciativas, após serem consideradas pelo Ministério Público Federal tentativas de violar o Direito Internacional dos Direitos Humanos, foram anuladas. Entretanto, elas sinalizam para um movimento orquestrado pela Bancada Ruralista e que tem se amplificado no atual Governo Federal.

Esse movimento fica notório desde o primeiro dia do mandato do presidente Jair Messias Bolsonaro. A Medida Provisória (MP) 870/2019 $9^{(6)}$, editada pelo presidente Bolsonaro em seu primeiro dia de governo, tinha a intenção de transferir a Funai para o recém-criado Ministério da Família, Mulher e dos Direitos Humanos e as atividades de demarcação para o Ministério da Agricultura, Pecuária e Abastecimento (MAPA), comandado pela Bancada Ruralista. Mais uma vez, a mobilização de indígenas, indigenistas e parlamentares foi fundamental para a não aprovação desse item, e a Funai manteve suas atividades no Ministério da Justiça e Defesa Civil.

Contudo, em 18 de junho de 2019, o Presidente da República, de forma inconstitucional, reeditou essa MP 870/2019 rejeitada, transformando-a na MP 886/2019 ${ }^{(7)}$, que propunha retirar da Funai, novamente, a questão fundiária, entregando a pasta para o MAPA. O Congresso Nacional atuou rapidamente vedando a reedição dessa MP, considerando-a uma afronta ao texto constitucional. Esse fato demonstra o posicionamento do Presidente da República frente às questões indígenas, de querer, de qualquer forma, expropriar os indígenas de seus territórios, tendo como justificativa o desenvolvimento do agronegócio e da economia do país.

Essas medidas evocam o processo histórico de expulsões e remoções forçadas dos indígenas das suas terras tradicionais, executadas por diferentes entes federativos e frentes de expansão em prol de projetos desenvolvimentistas e para fins de colonização. O governo da extrema direita reacende ideais positivistas e evolucionistas de "ordem, progresso e desenvolvimento" na base da bala, do coronelismo, patrimonialismo e nepotismo, características que demonstram o racismo estrutural e socioambiental existente no Brasil. 
Esse cenário político é relevante para a discussão sobre a saúde de povos indígenas, porque traz consequências diretas para as condições de vida desses povos. O Brasil é um país com grande diversidade étnica. São 305 povos indígenas, falando mais de 274 línguas, e 64\% habitando terras indígenas e áreas rurais $^{(8)}$. A garantia da posse e segurança de seus territórios exige articulações entre os diversos agentes políticos do campo indigenista. O principal desafio para a atenção à saúde é incorporar as demandas e as particularidades étnicas, culturais e epidemiológicas desses vários contextos socioambientais, isto é, de indígenas aldeados, na cidade, isolados e ameaçados pelos conflitos de terra ${ }^{(9)}$.

Os trabalhadores em saúde atuam em espaços sociais e geográficos conflituosos e precisam estar cotidianamente atentos à produção de um cuidado dialógico, pois as sociedades indígenas possuem seu próprio sistema terapêutico com concepções distintas de corpo, doença, tratamento, além de terem racionalidades que consideram as relações entre o território, a natureza, as forças humanas e espirituais. Portanto, as atividades desenvolvidas nos serviços de saúde que atendem a esses povos demandam ações interculturais diferenciadas.

O reconhecimento dessa especificidade cultural ocorreu com a promulgação da CF. Contudo, somente em 1999, houve a inserção desses povos no Sistema Único de Saúde (SUS), com a criação de 34 Distritos Sanitários Especiais Indígenas (DSEI), unidades gestoras descentralizadas do Subsistema de Atenção à Saúde Indígena. Os territórios dos DSEI foram constituídos com base na ocupação geográfica das comunidades indígenas, não coincidindo com o espaço geográfico de municípios ou estados, condição que traz desafios para a organização e articulação da atenção primária com outras esferas de atenção à saúde. De modo simplificado, a atenção primária de saúde é prestada nas aldeias, e os indígenas são referenciados para serviços municipais/estaduais de saúde para atenção de média e alta complexidade, conforme prerrogativas do SUS.

No momento da implementação do subsistema, prevalecia uma política neoliberal que preconizava a menor participação do Estado nas políticas sociais ${ }^{(10)}$. Assim, optou-se pela terceirização da assistência à saúde, com a contratação de entidades privadas e organizações não governamentais para a execução das ações nas aldeias. Essas instituições têm realizado a contratação de profissionais de saúde via processo seletivo temporário, fragilizando toda a proposta.

Em 2010, após intensa mobilização e reivindicação dos povos indígenas, foi criada a Secretaria Especial de Saúde Indígena (Sesai) no Ministério da Saúde. Este passou a gerenciar diretamente as ações de saúde e de saneamento básico e ambiental das terras indígenas. Antes disso, essas ações eram desenvolvidas de forma esporádica (campanhas) por diferentes órgãos governamentais, dentre eles o SPI, Funai e Fundação Nacional de Saúde, com avanços e retrocessos em cada época.

A Sesai foi dividida em três áreas - Departamento de Gestão da Saúde Indígena, Departamento de Atenção à Saúde Indígena e Distritos Sanitários Especiais Indígenas - e seria a única a fazer a gestão e execução das ações de saúde dentro do Ministério. No entanto, manteve-se a contratação de entidades e organizações de assistência social para prestação de serviços na atenção à saúde indígena. Em 2018 oito instituições foram habilitadas para executar tais atividades nos 34 DSEI.

Em maio de 2019, novo decreto assinado pelo presidente Jair Bolsonaro (Decreto n. 9.597) ${ }^{(11)}$, trouxe mudanças no modelo de gestão, na estrutura regimental e nos cargos em comissões e funções de confiança do Ministério da Saúde. Dentre as alterações está a extinção do Departamento de Gestão da Saúde Indígena e da Comissão Nacional de Política Indígena, que atuava como interlocutora entre etnias e gestão federal. Para algumas lideranças, o decreto é mais uma tentativa de restringir os direitos indígenas, deixando esses povos ainda mais vulneráveis.

A maior preocupação está no uso do termo integração ao SUS, repetidamente citado no texto. Uma vez que o subsistema já faz parte do SUS, não fica claro de que forma pretende-se integrá-lo, pois o então Ministro da Saúde referiu a necessidade de repassar parte dos serviços para os municípios e estados. Nesse caso, a proposta é a municipalização da atenção primária ofertada nas aldeias? O decreto 
em si não menciona a municipalização, mas, em um governo anti-indígena e contrário ao SUS, isso pode gerar grandes prejuízos para os indígenas.

O subfinanciamento do SUS impede a sua efetivação como política nacional de saúde. Nos municípios com maior proximidade às terras indígenas, isso é observado na precária oferta de serviços. Nessa conjuntura econômica e política, a municipalização das ações primárias de saúde não encontraria receptividade, e as populações indígenas, possivelmente, ficariam em situação ainda mais marginal. Além disso, setores sociais conservadores locais têm estabelecido relações preconceituosas e discriminatórias com os indígenas, o que afeta negativamente a distribuição de recursos a eles destinados.

Com base neste relato, observa-se a situação de insegurança e instabilidade dos direitos dessas populações, tendo em vista a destruição de políticas desenvolvidas ao longo de mais de 30 anos, em um processo de enfretamentos e debates entre estudiosos, indigenistas, lideranças e governos. Este é mais um indicativo da fragilidade do nosso Estado Democrático de Direito.

O direito à saúde no Brasil vem sendo aniquilado por diversas emendas constitucionais propostas por parlamentares que apoiam a política neoliberal instituída nos últimos governos federais e por sucessivos cortes nos recursos orçamentários. Embora possam parecer insignificantes em um primeiro momento, essas medidas, em conjunto, demonstram uma estratégia para minar a democracia e, por conseguinte, os direitos adquiridos com a promulgação da Constituição Federal ${ }^{(2)}$. É a efetivação do Estado mínimo, conforme reza a cartilha do neoliberalismo para as Américas Latina e do Sul.

Ainda não se sabe como todas essas alterações afetarão os DSEI, mas o contingenciamento do orçamento federal já trouxe repercussões para a Sesai, que enfrenta dificuldades para fixar profissionais de saúde, não conseguindo repassar recursos para as conveniadas, fato que atrasa o pagamento de salários e a compra de medicamentos e insumos. Em uma economia de escassez, a insegurança, a incerteza e a falta de garantia da manutenção de direitos básicos são ingredientes para uma progressiva erosão da democracia.

\section{Colaborações:}

1 - concepção, projeto, análise e interpretação dos dados: Silvia Angela Gugelmin e Jhéssika Angel Alves e Silva;

2 - redação do artigo e revisão crítica relevante do conteúdo intelectual: Silvia Angela Gugelmin e Jhéssika Angel Alves e Silva;

3 - aprovação final da versão a ser publicada: Silvia Angela Gugelmin e Jhéssika Angel Alves e Silva.

\section{Referências}

1. Brasil. Presidência da República. Lei no 6.001, de 19 de dezembro de 1973. Dispõe sobre o Estatuto do Índio [Internet]. Brasília (DF); 1973 [cited 2019 Nov 1]. Available from: http://www.planalto.gov.br/ccivil_03/Leis/ L6001.html

2. Brasil. Senado Federal. Constituição Federal (Texto promulgado em 5/10/1988). Constituição da República Federativa do Brasil [Internet]. Brasília (DF); 1988 [cited 2019 Nov 1]. Available from: http://www.senado.leg.br/ atividade/const/con1988/CON1988_05.10.1988/CON1988.asp

3. Brasil. Câmara dos Deputados. PEC 215/2000. Proposta de Emenda à Constituição. Acrescenta o inciso XVIII ao art. 49; modifica o $₫ 4^{\circ}$ e acrescenta o $₫ 8^{\circ}$ ambos no art. 231, da Constituição Federal [Internet]. Brasília (DF); 2000 Mar 28 [cited 2019 Nov 1]. Available from: http://www.camara.gov.br/proposicoesWeb/fichadetramitacao?id Proposicao $=14562$

4. Machado R. "Nós não somos donos da terra, nós somos a terra". Entrevista especial com Casé Angatu Xukuri Tubinambá. São Leopoldo (RS): Instituto Humanitas Unisinos; 2019 jan 31. [cited 2019 Nov 18]. Available from: 
http://www.ihu.unisinos.br/159-noticias/entrevistas/582140-nos-nao-somos-donos-da-terra-nos-somos-a-terraentrevista-especial-com-case-angatu-xukuru-tupinamba

5. Brasil. Parecer no 001/2017/GAB/CGU/AGU. Estabelece o dever da Administração Pública Federal, direta e indireta, de observar, respeitar e dar efetivo cumprimento, de forma obrigatória, às condições fixadas na decisão do Supremo Tribunal Federal na PET 3.388/RR em todos os processos de demarcação de terras indígenas. Brasília (DF); 2017. Diário Oficial da União. Brasília (DF); 201720 jul; ed. 138; Seção 1:7-11.

6. Brasil. Medida Provisória no 870/2019. Convertida com alteração na Lei Ordinária 13.844, de 18 de junho de 2019. Estabelece a organização básica dos órgãos da Presidência da República e dos Ministérios. Diário Oficinal da União. Brasília (DF); 201918 jun; ed. extra; Seção 1:4.

7. Brasil. Medida Provisória no 886/2019. Altera a Lei no 13.844, de 18 junho de 2019, a Lei no 8.171 , de 17 de janeiro de 1991, a Lei no 12.897, de 18 de dezembro de 2013, a Lei no 9.613, de 3 de março de 1998, e a Lei n⿳0 13.334, de 13 de setembro de 2016, para dispor sobre a organização básica dos órgãos da Presidência da República e dos Ministérios. Brasília; 2019. Diário Oficinal da União. Brasília (DF): 201919 jun; ed. 117; Seção 1:2.

8. Instituto Brasileiro de Geografia e Estatística. O Brasil Indígena. Os indígenas no Censo Demográfico 2010. Crescimento no período 1991/2010. Categorias cor ou raça [Internet]. Rio de Janeiro; 2012 [cited 2019 Nov 20]. Available from: https://indigenas.ibge.gov.br/pt/estudos-especiais-3/o-brasil-indigena/ os-indigenas-no-censo-demografico-2010

9. Cardoso MD. Saúde e povos indígenas. Cad Saúde Pública. 2014;30(4):860-6.

10. Garnelo L. Política de Saúde Indígena no Brasil: notas sobre as tendências atuais do processo de implantação do subsistema de atenção à saúde. In: Garnelo L, Pontes AL, organizadoras. Saúde Indígena: uma introdução ao tema [Internet]. Brasília: MEC-SECADI; 2012. (Coleção Educação para Todos. Série Vias dos Saberes n. 5). p. 18-58 [cited 2019 Nov 20]. Available from: http://bvsms.saude.gov.br/bvs/publicacoes/saude_indigena_uma_ introducao_tema.pdf

11. Brasil. Câmara dos Deputados. Decreto no 9.795, de 17 de maio de 2019. Aprova a Estrutura Regimental e o Quadro Demonstrativo dos Cargos em Comissão e das Funções de Confiança do Ministério da Saúde, remaneja cargos em comissão e funções de confiança, transforma funções de confiança e substitui cargos em comissão do Grupo-Direção e Assessoramento Superiores - DAS por Funções Comissionadas do Poder Executivo - FCPE [Internet]. Brasília (DF); 2019 [cited 2019 Nov 1]. Available from: http://www.planalto.gov.br/ccivil_03/_ato20192022/2019/decreto/D9795.htm

Recebido: 30 de novembro de 2019

Aprovado: 9 de novembro de 2020

Publicado: 1 de dezembro de 2020

A Revista Baiana de Enfermagem utiliza a Licença Creative Commons - Atribuição-NãoComercial 4.0 Internacional. https://creativecommons.org/licenses/by-nc/4.0/ Este artigo é de acesso aberto distribuído sob os termos da Licença Creative Commons (CC BY-NC). Esta licença permite que outros remixem, adaptem e criem a partir do seu trabalho para fins não comerciais. Embora os novos trabalhos tenham de lhe atribuir o devido crédito e não possam ser usados para fins comerciais, os usuários não têm de licenciar esses trabalhos derivados sob os mesmos termos. 